\section{Identification of Preussin as a Selective Inhibitor for Cell Growth of the Fission Yeast $t s$ Mutants Defective in $\mathrm{Cdc2}$-Regulatory Genes}

\author{
Koji Kasahara, Minoru Yoshida*, \\ Jun Eishima, KazUTOH TaKesako ${ }^{\dagger}$, \\ Teruhiko $\mathrm{BePPU}^{\dagger \dagger}$ and Sueharu Horinouchi \\ Department of Biotechnology, \\ Graduate School of Agriculture and Life Sciences, \\ The University of Tokyo, \\ Bunkyo-ku, Tokyo 113, Japan, \\ ${ }^{\dagger}$ Biotechnology Research Laboratories, \\ Takara Shuzo Co. Ltd., \\ Otsu-shi, Shiga 520-21, Japan
}

(Received for publication December 18, 1996)

Recent studies have revealed that cell cycle control in G1 or G2 phase is the basis for understanding the mechanism for tumorigenesis ${ }^{1,2)}$. It is therefore likely that inhibitors of G1 and/or G2 progression are candidates for a new type of chemotherapeutic agents. Since the cell cycle regulators such as cyclins and CDKs are highly conserved from yeast to humans, screening for inhibitors of the yeast cell cycle seems to be one of the promising ways leading to identification of mammalian cell cycle inhibitors. The $c d c$ mutants containing temperature-sensitive cell cycle regulators are incapable of progressing through a specific stage of the cell cycle at the nonpermissive temperature ${ }^{3)}$. In addition, $c d c$ mutants often show altered sensitivity to agents targeting the $c d c$ gene products at the permissive temperature ${ }^{4,5}$. We therefore performed a panel screening using several $c d c$ mutants of Schizosaccharomyces pombe in order to identify compounds to which these $c d c$ mutants showed hyper-sensitivity. The mutants we used were $c d c 2, c d c 13$, $c d c 25$, and weel, all of which are involved in controlling the M-phase promoting factor associated with $c d c 2$ kinase activity ${ }^{6}$. The $c d c 2$ kinase plays a key role in G1 and G2 progression in $S$. pombe ${ }^{7,8)}$. $c d c 13$ encodes a B-type cyclin that is associated with $\mathrm{Cdc} 2$ kinase and necessary for its catalytic activity, $c d c 25$ encodes a protein-tyrosine phosphatase that dephosphorylates the kinase-inhibitory phosphotyrosine-15 residue on Cdc2 kinase and thereby activates $\mathrm{Cdc} 2$, and weel encodes a protein-tyrosine kinase that phosphorylates the tyrosine residue and thus acts as a negative regulator for $\mathrm{Cdc} 2$. These regulators as well as Cdc2 are highly conserved in all eukaryotes ${ }^{9}$.

In the course of our screening program, we found a strong activity in the broth of a fungus Aspergillus sp. strain 693, which inhibited the proliferation of $c d c 25$, $c d c 13$, and weel but did not produce any visible in- hibitory zone on the wild-type or other $c d c$ strains in the paper disc assay. For purification of the active substance, the producing strain 693 was cultivated in 5 litters of YMPG medium containing glucose $2 \%$, yeast extract $0.5 \%$, malt extract (Difco) $0.5 \%$, and Bactopeptone (Difco) $0.5 \%$, for 5 days at $26.5^{\circ} \mathrm{C}$. The active substance was extracted with hexane - ethylacetate $(9: 1)$ from both the mycelial acetone extract and the cultured supernatant. The concentrated material was dissolved in hexaneethylacetate $(9: 1)$ and successively fractionated by a silica gel column $(50 \times 100 \mathrm{~mm}, 200 \mathrm{ml})$ with a solvent system of a gradient of hexane - ethylacetate (from 9:1 to $1: 1$ ) and by silica gel thin layer chromatography (Merck Art. 15389) using a solvent system composed of ethylacetate - methanol $(1: 1)$ to give a broad spot at $\mathrm{Rf}$ $0 \sim 0.25$ by iodine visualization. The active compound was recovered from the silica gel plate, giving $5.0 \mathrm{mg}$ of an active compound as yellow wax.

The active compound was soluble in chloroform, ethylacetate, acetone, and methanol, but almost insoluble in hexane and $\mathrm{H}_{2} \mathrm{O}$, and was optically active $\left([\alpha]_{\mathrm{D}}=+21.8^{\circ}\right.$ $\left.\left(c=0.66 \mathrm{CHCl}_{3}\right)\right)$. FAB mass spectrometries exhibited its ion peak $(\mathrm{M}+\mathrm{H})^{+}$at $m / z 318$, suggesting that the molecular formula of this compound is $\mathrm{C}_{21} \mathrm{H}_{35} \mathrm{NO}$. These data together with other spectroscopic analyses indicate that the compound is identical to preussin (synonymous with L-657,398), which was previously reported as an antifungal antibiotic ${ }^{10,11)}$ (Fig. 1). Preussin is structurally related to anisomycin, an anti-protozoan and anti-yeast compound isolated from Streptomyces griseolus and Streptomyces roseochromogenes ${ }^{12)}$. Anisomycin was reported to be an inhibitor of protein synthesis in certain yeasts and mammalian cells ${ }^{13)}$. However, anisomycin caused strong growth inhibition on all the strains tested, suggesting that the target molecule of preussin is different from that of anisomycin (data not shown).

Minimal inhibitory concentrations (MICs) of preussin against $S$. pombe $c d c$ mutants were determined by a conventional agar dilution method. As shown in Table 1 , the MICs of preussin for $c d c 13, c d c 25$, weel, and wee1disrupted strains were $24 \mathrm{ng} / \mathrm{ml}, 12 \mathrm{ng} / \mathrm{ml}, 391 \mathrm{ng} / \mathrm{ml}$, and $196 \mathrm{ng} / \mathrm{ml}$, respectively. These mutants were 100 to 1000-fold more sensitive to preussin compared with wild-type $S$. pombe, since the MIC of preussin for the wild-type strain was $12.5 \mu \mathrm{g} / \mathrm{ml}$. To determine whether

Fig. 1. Chemical structure of preussin.

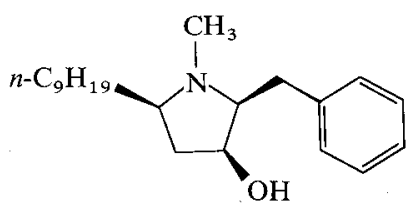

Present affiliation: ${ }^{\dagger \dagger}$ Department of Applied Biological Science, College of Bioresource Sciences, Nihon University, Kame-ino, Fujisawa-shi, Kanagawa 252, Japan 
Table 1. Minimal inhibitory concentrations of preussin against the fission yeast $c d c$ mutants.

\begin{tabular}{lc|cc}
\hline & $\mathrm{MIC}(\mu \mathrm{g} / \mathrm{ml})$ & & $\mathrm{MIC}(\mu \mathrm{g} / \mathrm{ml})$ \\
\hline Wild type & 12.5 & $c d c 13$ & 0.024 \\
$c d c 1$ & 12.5 & $c d c 14$ & 6.25 \\
$c d c 2$ & 6.25 & $c d c 15$ & 0.781 \\
$c d c 3$ & 6.25 & $c d c 16$ & 12.5 \\
$c d c 4$ & 0.781 & $c d c 17$ & 12.5 \\
$c d c 5$ & 1.56 & $c d c 18$ & 12.5 \\
$c d c 6$ & 6.25 & $c d c 19$ & 6.25 \\
$c d c 7$ & 6.25 & $c d c 20$ & 12.5 \\
$c d c 8$ & 6.25 & $c d c 21$ & 12.5 \\
$c d c 9(w e e 1)$ & 0.391 & $c d c 22$ & 12.5 \\
$c d c 10$ & 12.5 & $c d c 23$ & 6.25 \\
$c d c 11$ & 12.5 & $c d c 25$ & 0.012 \\
$c d c 12$ & 6.25 & $\Delta w e e 1$ & 0.196 \\
\hline
\end{tabular}

the supersensitivity of these mutants to preussin is due to the respective $c d c$ gene mutations, we analyzed the phenotypes of their tetrads crossed with the wild-type strain. All the $t s$ segregants were supersensitive to preus$\sin$. These results showed that the $c d c$ mutations themselves were responsible for the preussin sensitivity.

$\mathrm{Cdc} 2$ is a serine/threonine kinase that acts as a major regulator of the eukaryotic cell cycle. In $S$. pombe, $c d c 2$ regulates the initiation of both $S$ and $M$ phases and its timing of activation is strictly regulated by $c d c 13, c d c 25$, and weel gene products ${ }^{6)}$. We therefore tested whether preussin directly inhibited Cdc2 kinase activity of $S$. pombe. The active $\mathrm{Cdc} 2 / \mathrm{Cdc} 13$ complex was extracted by using $\mathrm{p} 13^{\text {sucl }}$ beads ${ }^{14)}$, and the effect of preussin on the kinase activity was determined by incorporation of $\left[{ }^{32} \mathrm{P}\right]$ into histone $\mathrm{Hl}$ from $\left[{ }^{32} \mathrm{P}-\gamma\right] \mathrm{ATP}$, as described previously ${ }^{15)}$. The catalytic activity of $\mathrm{Cdc} 2$ was not inhibited by preussin even at very high concentrations (i.e., greater than $250 \mu \mathrm{g} / \mathrm{ml}$, data not shown). The effects on Cdc25 phosphatase and Wee1 kinase were determined by using recombinant proteins of their human homo$\operatorname{logs}{ }^{16,17)}$, since they possess essentially the same activity as those from $S$. pombe $e^{9)}$. The C-terminal kinase domain of human Weel was produced in $E$. coli and used for Wee1 kinase assay ${ }^{17)}$. The recombinant protein produced as an inclusion body was solubilized with $6 \mathrm{M}$ urea, separated by DEAE chromatography, and refolded with a step-wise dilution of urea. The activity of Weel kinase was assayed by phosphorylation of human $\mathrm{Cdc} 2$-cyclin B complex or auto-phosphorylation. Human Cdc25 was expressed as a fusion protein with glutathion $S$-transferase (GST) in $E$. coli, and purified with a glutathionSepharose column $(12 \times 100 \mathrm{~mm})^{16)}$. Similarly to the effect on Cdc2 kinase, preussin did not inhibit their activity in vitro at high concentrations more than $50 \mu \mathrm{g} / \mathrm{ml}$ (data not shown). We therefore concluded that $\mathrm{Cdc} 2$ kinase, Cdc25 phosphatase, or Weel kinase is not the direct target of preussin. However, it is still possible that preussin may interfere with the in vivo activation of these regulators. It is also possible that preussin may affect the
Fig. 2. Effect of preussin on $3 Y 1$ cells.

A, control cells without treatment; B, $1 \mu \mathrm{g} / \mathrm{ml}$ preussin; C, $10 \mu \mathrm{g} / \mathrm{ml}$ preussin; D, $100 \mu \mathrm{g} / \mathrm{ml}$ preussin.

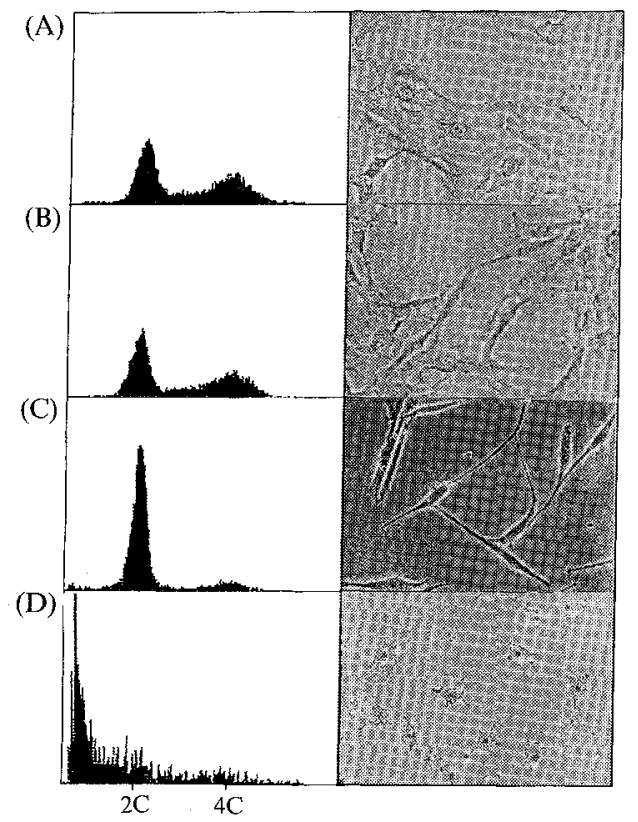

Normal rat fibroblast $3 \mathrm{Y} 1$ cells arrested at the early $\mathrm{S}$ phase were released by removing hydroxyurea and treated with various concentrations of preussin for 24 hours. After taken the phase contrast photographs of each culture under a light microscope (right panel), the cells were collected and the cellular distribution of DNA contents was measured with a flow cytometer (left panel).

stability of the multi-protein complex containing $\mathrm{Cdc} 2$ and the $t s$ regulators.

Preussin caused growth inhibition not only of S. pombe but also mammalian cells. The $\mathrm{IC}_{50}$ of preussin for normal rat fibroblast $3 \mathrm{Y} 1$ cells was determined to be $5 \mu \mathrm{g} / \mathrm{ml}$ on the basis of the total cell number after treatment for 3 days. Strong cytotoxic activity was observed when more than $31.7 \mu \mathrm{g} / \mathrm{ml}$ of preussin was added to the exponentially growing culture of $3 Y 1$ cells. The effect of preussin on the mammalian cell cycle was analyzed by determining the distribution of cellular DNA contents in the early S phase synchronous culture of $3 \mathrm{Y} 1$ cells by flow cytometry ${ }^{18 \sim 20)}$ (Fig. 2). Fig. 2A shows a typical profile of DNA content distribution obtained with a control culture 24 hours after hydroxyurea removal. While the cytogram obtained with the culture treated with $1 \mu \mathrm{g} / \mathrm{ml}$ of preussin was almost the same as that of control, accumulation of the cells with 2C DNA content was observed when the cells had been treated with $10 \mu \mathrm{g} / \mathrm{ml}$ of preussin (Fig. 2B, C). Cell elongation was observed in the arrested cell culture. Exposure to $100 \mu \mathrm{g} /$ $\mathrm{ml}$ of preussin caused marked fragmentation of nuclei, suggesting that the high concentration of preussin induces apoptosis in rat $3 \mathrm{Y} 1$ fibroblasts. These results indicate that preussin inhibits G1 progression of the mammalian cell cycle in a relatively narrow concentration range and 
causes a cytotoxic effect at a high concentration.

The relationship between selective growth inhibition in $S$. pombe $c d c$ mutants and the G1 arrest in mammalian cells is unclear. In mammalian cells, there are multiple cyclin-dependent kinases (CDKs) structurally similar to $\mathrm{Cdc} 2$, and most of them are required for G1 progres$\operatorname{sion}^{2,21,22)}$. It is therefore conceivable that G1 cyclin/ CDKs-regulatory cascade is more sensitive to preussin than $\mathrm{G} 2$ cyclin/Cdc 2 cascade in mammalian cells. Further studies are needed for elucidation of molecular mechanism by which preussin induces selective growth inhibition of $S$. pombe $c d c$ mutants and Gl arrest in mammalian cells.

\section{Acknowledgments}

We are grateful to T. SHimODA, Osaka City University, for providing us with $S$. pombe $c d c$ mutants. We also thank $H$. SETO, Tokyo University, and H. YASUDA, Tokyo University of Pharmacy and Life Science, for the plasmids containing genes for GST-Cdc25 fusion protein and human Wee1, respectively. This work was supported in part by a special grant for Advanced Research on Cancer from the Ministry of Education, Culture and Science of Japan.

\section{References}

1) Hunter, T. \& J. Pines: Cyclins and cancer. Cell 66: $1071 \sim 1074,1991$

2) Hunter, T. \& J. Pines: Cyclins and cancer. II: Cyclin D and CDK inhibitors come of age. Cell 79: $573 \sim 582,1994$

3) Hartwell, L. H.; J. Culotti, J. R. Pringle \& B. J. Reid: Genetic control of the cell division cycle in yeast. Science 183: $46 \sim 51,1974$

4) Toda, T.; Y. Adachi, Y. Hiraoka \& M. Yanagida: Identification of the pleiotropic cell division cycle gene NDA2 as one of two different alpha-tubulin genes in Schizosaccharomyces pombe. Cell 37: $233 \sim 242,1984$

5) Hiraoka, Y.; T. TOda \& M. Yanagida: The NDA3 gene of fission yeast encodes beta-tubulin: a cold-sensitive nda3 mutation reversibly blocks spindle formation and chromosome movement in mitosis. Cell $349 \sim 358,1984$

6) NURSE, P.: Universal control mechanism regulating onset of M-phase. Nature 344: $503 \sim 508,1990$

7) Nurse, P. \& Y. BissetT: Gene required in G1 for commitment to cell cycle and in G2 for control of mitosis in fission yeast Schizosaccharomyces pombe. Nature 292: $558 \sim 560,1981$

8) Piggott, J. R.; R. Rai \& B. L. A. Carter: A bifunctional gene product involved in two phases of the yeast cell cycle. Nature 298: $391 \sim 394,1982$

9) Norbury, C. \& P. Nurse: Animal cell cycles and their control. Annu. Rev. Biochem. 61: 441 470, 1992

10) Schwarts, R. E.; J. Liesch, O. Hensens, L. Zitano, S. Honeycutt, G. Garrity, R. A. Fromtling, J. Onishi \& R. Monaghan: L-657,398, a novel antifungal agent: fermentation, isolation, structural elucidation and biological properties. J. Antibiotics 41: 1774 1779, 1988

11) Johnson, J. H.; D. W. Phillipson \& A. D. Kahle: The relative and absolute stereochemistry of the antifungal agent preussin. J. Antibiotics 42: 1184 1185, 1989

12) Sobin, B. A. \& J. F. W. Tanner: Anisomycin, a new antiprotozoan antibiotic. J. Am. Chem. Soc. 76: 4053, 1954

13) Grolloman, A. P.: Inhibitors of protein biosynthesis. II. Mode of action of anisomycin. J. Biol. Chem. 242: 3226 3233, 1967

14) Arion, D.; L. Meijer, L. Brizuela \& D. BeaCh: $c d c 2$ is a component of the M-phase specific histone H1 kinase: evidence for identity with MPF. Cell 55: 371 378, 1988

15) Usui, T.; M. Yoshida, K. Abe, H. Osada, K. Isono \& T. BEPPU: Uncoupled cell cycle without mitosis induced by a protein kinase inhibitor, K-252a. J. Cell Biol. 115: $1275 \sim 1282,1991$

16) Galaktionov, K. \& D. Beach: Specific activation of cdc25 tyrosine phosphatases by B-type cyclins: evidence for multiple roles of mitotic cyclins. Cell 67: $1181 \sim 1194$, 1991

17) Honda, R.; Y. Ohba \& H. Yasuda: The cell cycle regulator, human $\mathrm{p} 50^{\text {weel }}$, is a tyrosine kinase and not a serine/tyrosine kinase. Biochem. Biophys. Res. Commun. 186: $1333 \sim 1338,1992$

18) Yoshida, M.\& T. Beppu: Reversible arrest of proliferation of rat $3 \mathrm{Y} 1$ fibroblasts in both the G1 and G2 phases by trichostatin A. Exp. Cell Res. 177: 122 131, 1988

19) Aвe, K.; M. Yoshida, T. Usui, S. Horinouchi \& T. BEPPU: Highly synchronous culture of fibroblasts from G2 block caused by staurosporine, a potent inhibitor of protein kinases. Exp. Cell Res. 192: 122 127, 1991

20) ABe, K.; M. Yoshida, S. Horinouchi \& T. Beppu: Leptolstatin from Streptomyces sp. SAM1595, a new gap phase-specific inhibitor of the mammalian cell cycle. I. Screening, taxonomy, purification and biological activities. J. Antibiotics 46: 728 734, 1993

21) SHerr, C. J.: Mammalian G1 cyclins. Cell 73: $1059 \sim 1065$, 1993

22) SHERr, C. J.: G1 phase progression: cycling on cue. Cell 79: $551 \sim 555,1994$ 